\title{
Extended State Observer Based Adaptive Back-Stepping Sliding Mode Control of Electronic Throttle in Transportation Cyber-Physical Systems
}

\author{
Yongfu Li, Bin Yang, Taixiong Zheng, and Yinguo Li \\ College of Automation, Chongqing University of Posts and Telecommunications, Chongqing 400065, China \\ Correspondence should be addressed to Yongfu Li; liyongfu@cqupt.edu.cn
}

Received 26 November 2014; Revised 11 January 2015; Accepted 27 January 2015

Academic Editor: Xinggang Yan

Copyright (C) 2015 Yongfu Li et al. This is an open access article distributed under the Creative Commons Attribution License, which permits unrestricted use, distribution, and reproduction in any medium, provided the original work is properly cited.

Considering the high accuracy requirement of information exchange via vehicle-to-vehicle (V2V) communications, an extended state observer (ESO) is designed to estimate the opening angle change of an electronic throttle (ET), wherein the emphasis is placed on the nonlinear uncertainties of stick-slip friction and spring in the system as well as the existence of external disturbance. In addition, a back-stepping sliding mode controller incorporating an adaptive control law is presented, and the stability and robustness of the system are analyzed using Lyapunov technique. Finally, numerical experiments are conducted using simulation. The results show that, compared with back-stepping control (BSC), the proposed controller achieves superior performance in terms of the steady-state error and rising time.

\section{Introduction}

Transportation cyber-physical systems (T-CPS) aim to achieve full coordination and optimization of transportation systems, via the increased interaction and feedback between the transportation cyber systems and transportation physical systems [1-3]. For example, in the vehicle platoon, the desired control objective is that all vehicles in that platoon move with a safe space headway and a safe speed. Once an accident occurs in front of the platoon, the leading car must take an emergency brake to avoid collision, and then the following vehicles will respond to the front vehicles correspondingly. In this context, the $\mathrm{V} 2 \mathrm{~V}$-based communication of information on the opening angle of the electronic throttle (ET) of the preceding vehicles in a lane enables a following vehicle to react as fast as possible to avoid a collision by adaptively adjusting its ET. On the other hand, an elegantly designed controller could be applied for the throttle to track the desired valve opening angle, which can improve the fuel economy, emissions, and vehicle drivability [4].

Based on traffic models, many researchers have demonstrated that the headway spacing between preceding vehicles and following vehicles can be kept safe via speed controllers, which can effectively guarantee the stability of platoon of vehicles and avoid collision [5-10]. Since the vehicle speed is related to the opening angle of the ET [5], the stability of the platoon of vehicles is associated with electronic throttle control (ETC). However, the ETC with high performance is a challenging problem, due to the nonlinear factors such as parametric uncertainty, stick-slip friction, gear backlash, and nonlinear spring [11-14]. Consequently, the study on control strategy for ET has attracted considerable attention in recent years.

Several control strategies have been proposed to improve the performance of ETC including (i) linear control [12, 13], (ii) optimal control [15-17], (iii) sliding mode control [18-21], (iv) model approximation control $[14,22]$, and (v) intelligent control [11, 23-27]. Deur et al. [12,13] propose a proportionalintegral-derivative (PID) controller that compensates the effects of friction and limp-home using a feedback compensator. Vašak et al. [15] propose a model predictive optimal controller to handle with nonlinearities. However, the mixedinteger programming cannot be implemented in a real-time manner due to its computational complexity. Subsequently, 
Vašak et al. [16] deal with this problem through the precomputation of the state feedback control in the process of dynamic programming offline. Nevertheless, the control law obtained from a look-up table will lead to the deterioration of control performance. On the other hand, sliding mode control (SMC) for ET has attracted more attention due to its strong robustness. Horn and Reichhartinger [19] propose a high-order SMC to design ET controller, and then the twisting and the supertwisting algorithm are used to eliminate the impacts of chattering caused by the variable structure. Furthermore, Pan et al. [20] put forward the sliding mode observer based SMC for ET valve. However, compared with [19], the work of [20] does not reject the influences of chattering effectively. Recently, Bai and Tong [21] propose the adaptive back-stepping SMC for ET system. However, they assume that the throttle opening angle change is measurable, which is not true in practice.

Recently, intelligent approaches have been widely used in the engine control, such as controller design, parameter identification, or fault diagnosis. Sheng and Bao [26] propose a fractional order fuzzy-PID controller for ET, and the fruit fly optimization algorithm is used to search for the optimal values of the controller parameters. However, the gear backlash torque is ignored in this control strategy, which plays an important role in the controller design. Wang and Huang [27] put forward an intelligent fuzzy controller with a feedforward term to deal with the nonlinear hysteretic of ET. Meanwhile, the new closed-loop back-propagation tuning is also proposed for the fuzzy output membership function to get better tracking performance. Unfortunately, the fuzzy rule for the feedforward controller is designed too simple to illustrate the characteristics of the nonlinear hysteresis. Moreover, with the development of automobile electronic technology, Yadav and Gaur [28] put the ETC into the uncertain hybrid electric vehicle (HEV) speed control, where a self-tuning fuzzy PID controller and a special sliding mode adaptation mechanism are developed to achieve the robust performance of the ET controlled HEV. However, the use of the sign function in the SMC brings highfrequency chattering, which usually causes serious problems for actuators in real applications.

Since it is extremely difficult to measure those signals including the opening angle change of ET, the nonlinear factors, and external disturbance, $\mathrm{Hu}$ et al. [4] use a reducedorder observer to estimate the throttle opening angle change. Thereafter, a back-stepping controller is designed for ETC based on Lyapunov techniques. However, the accuracy of the proposed method relies heavily on the precise information of the throttle; thus its robustness to estimation error should be improved. Moreover, the effect of torque caused by air flow and parameters variation is ignored in the algorithm, which is significant for the practical performance of the ETC.

Regarding the aforementioned issues, an extended state observer (ESO) based adaptive back-stepping sliding mode controller for ET valve is proposed in this paper, and then an adaptive control law is further designed using Lyapunovbased techniques. Finally, the numerical experiments are conducted and the results show that the combination of

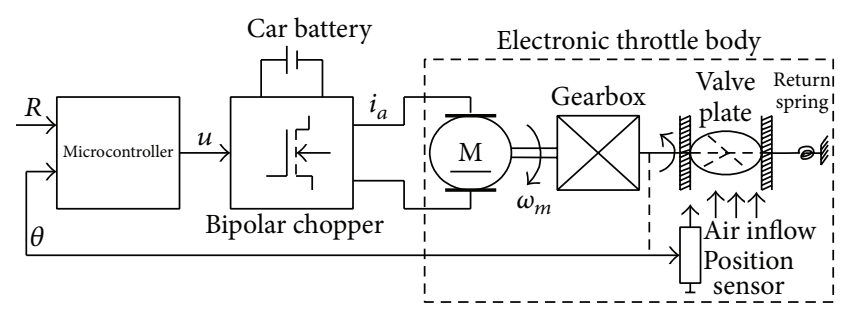

FIgURE 1: The control structure of ET.

the adaptive back-stepping and SMC can improve the performance of ETC in terms of the steady error and the rising time.

The rest of this paper is organized as follows. Section 2 describes the mathematical model of the ET system including friction, nonlinear spring, and gear backlash. Section 3 designs an ESO for ET. Section 4 proposes an adaptive backstepping SMC controller. Section 5 performs simulationbased numerical experiments and compares the performance of the proposed controller with that of BSC controllers. The final section provides some concluding remarks.

\section{Model}

As shown in Figure 1, ET valve consists of a DC motor, a gearbox, a valve plate, a position sensor, and a dual return spring [11].

According to Kirchhoff's law, the model of the motor winding circuit is as follows [4]:

$$
L_{a} \frac{\mathrm{d} i_{a}}{\mathrm{~d} t}+R_{a} i_{a}=k_{\mathrm{ch}} u-k_{v} \dot{\theta}_{m}
$$

where $L_{a}$ and $R_{a}$ are the armature inductance and the overall resistance of the armature circuit, respectively. And $i_{a}, u$ represent the dc motor armature current and the input control voltage, respectively. $k_{\mathrm{ch}}$ and $k_{v}$ denote the chopper gain and the electromotive force constant, and $\dot{\theta}_{m}$ is the motor angular velocity.

In terms of the torque balance principle, the dynamic characteristic of throttle valve is given by [4]

$$
J k_{l}^{2} \ddot{\theta}=k_{l} k_{t} i_{a}-T_{s}-T_{f}-T_{l}
$$

where $\theta$ is the position (opening angle) of throttle valve, $J$ is the overall moment of inertia with respect to the motor side, $k_{t}$ is motor torque constant, $T_{s}$ is the throttle return spring torque, $T_{l}$ is the torque caused by the air flow, and $k_{l}=\theta_{m} / \theta$ is gear ratio. $T_{f}$ is frictional torque caused by Coulomb and sliding friction as follows [4]:

$$
T_{f}=k_{t f} \operatorname{sgn}(\dot{\theta})+k_{f} \dot{\theta},
$$

where $k_{t f}$ is Coulomb friction coefficient and $k_{f}$ is sliding friction coefficient. In addition, the throttle return spring torque $T_{s}$ is given by [4]

$$
T_{s}=k_{\mathrm{sp}}\left(\theta-\theta_{0}\right)+k_{\mathrm{pre}} \operatorname{sgn}\left(\theta-\theta_{0}\right),
$$


where $k_{\mathrm{sp}}$ is spring elastic coefficient, $k_{\text {pre }}$ is the spring tightening torque coefficient, and $\theta_{0}$ is the default opening angle of the ET.

The system sampling time is chosen with respect to the dominant time constant of the linearized ET model and is set to $T=5 \mathrm{~ms}$ [12]. The armature current dynamics can be neglected since the time constant $T_{a}=L_{a} / R_{a} \leq T$. Therefore, (1) can be simplified as $[12,15]$

$$
i_{a}=\frac{1}{R_{a}}\left(k_{\mathrm{ch}} u-k_{v} \dot{\theta}_{m}\right) .
$$

Based on (2)-(5), the ET model is

$$
\begin{gathered}
\ddot{\theta}=\frac{1}{k_{l}^{2} J}\left[\frac{k_{l} k_{t} k_{\mathrm{ch}}}{R_{a}} u-\left(\frac{k_{l}^{2} k_{t} k_{v}}{R_{a}}+k_{f}\right) \dot{\theta}-k_{\mathrm{pre}} \operatorname{sgn}\left(\theta-\theta_{0}\right)\right. \\
\left.-k_{\mathrm{sp}}\left(\theta-\theta_{0}\right)-k_{t f} \operatorname{sgn}(\dot{\theta})-T_{l}\right] .
\end{gathered}
$$

Then, let $x_{1}=\theta$ and $x_{2}=\dot{\theta}$; the state-space expression of (6) can be written as

$$
\left[\begin{array}{c}
\dot{x}_{1} \\
\dot{x}_{2}
\end{array}\right]=\left[\begin{array}{cc}
0 & 1 \\
\frac{-k_{\mathrm{sp}}}{k_{l}^{2} J} & A_{1}
\end{array}\right]\left[\begin{array}{l}
x_{1} \\
x_{2}
\end{array}\right]+\left[\begin{array}{l}
0 \\
B
\end{array}\right] u+\left[\begin{array}{c}
0 \\
C\left(x_{1}, x_{2}\right)
\end{array}\right],
$$

where $A_{1}=-\left(k_{l}^{2} k_{t} k_{v}+k_{f} R_{a}\right) / k_{l}^{2} J R_{a}, B=k_{t} k_{\mathrm{ch}} / k_{l} J R_{a}$, and $C\left(x_{1}, x_{2}\right)=\left(-k_{\text {pre }} \operatorname{sgn}\left(\theta-\theta_{0}\right)+k_{\text {sp }} \theta_{0}\right) / k_{l}^{2} J-\left(k_{t f} \operatorname{sgn}(\dot{\theta})+T_{l}\right) /$ $k_{l}^{2} J$.

Let $d(t)$ represent the total disturbance including the combining the $\operatorname{sgn}(\dot{\theta})$, unknown $T_{l}$ (the torque caused by the air flow), and the external disturbance; we can rewrite (7) with consideration that the Coulomb friction coefficient $k_{t f}$ is very small as follows:

$$
\left[\begin{array}{c}
\dot{x}_{1} \\
\dot{x}_{2}
\end{array}\right]=\left[\begin{array}{cc}
0 & 1 \\
-k_{\mathrm{sp}} & A_{1}
\end{array}\right]\left[\begin{array}{l}
x_{1} \\
x_{2}^{2} J
\end{array}\right]+\left[\begin{array}{l}
0 \\
B
\end{array}\right] u+\left[\begin{array}{c}
0 \\
C\left(x_{1}\right)
\end{array}\right]+\left[\begin{array}{c}
0 \\
d(t)
\end{array}\right],
$$

where $A_{1}=-\left(k_{l}^{2} k_{t} k_{v}+k_{f} R_{a}\right) / k_{l}^{2} J R_{a}, B=k_{t} k_{\mathrm{ch}} / k_{l} J R_{a}$, and $C\left(x_{1}\right)=\left(-k_{\text {pre }} \operatorname{sgn}\left(\theta-\theta_{0}\right)+k_{\mathrm{sp}} \theta_{0}\right) / k_{l}^{2} J$.

Taking the parametric variations of ET into consideration, (8) can be further rewritten as

$$
\begin{aligned}
& \dot{x}_{1}=x_{2}, \\
& \dot{x}_{2}=(A+\Delta A) x+(B+\Delta B) u+\bar{d}(t),
\end{aligned}
$$

where $A=\left[-\left(\pi k_{\mathrm{sp}}+2 k k_{\mathrm{pre}}\right) / \pi k_{l}^{2} J A_{1}\right], \bar{d}(t)=\left(\left(\pi k_{\mathrm{sp}}+\right.\right.$ $\left.\left.2 k k_{\mathrm{pre}}\right) / \pi k_{l}^{2} J\right) \theta_{0}+d(t), k>0$.

Further, we have

$$
\dot{x}_{2}=A x+B u+F,
$$

where $F$ is the total uncertainty given by

$$
F=\Delta A \mathbf{x}+\Delta B u+\bar{d}(t),
$$

where $|F| \leq \bar{F} . \Delta A$ and $\Delta B$ are the system parametric uncertainties.

\section{Extended State Observer Design}

Since ESO can estimate the system states as well as disturbance, we use the ESO to estimate the opening angle change of ET [29-31]. Based on (8), the nonlinear system is designed as follows [29]:

$$
\begin{aligned}
& \dot{\vec{x}}_{1}=\widehat{x}_{2}-g_{1}\left(\widehat{x}_{1}-x_{1}\right), \\
& \dot{\vec{x}}_{2}=\widehat{x}_{3}-g_{2}\left(\widehat{x}_{1}-x_{1}\right)+B u, \\
& \dot{\hat{x}}_{3}=-g_{3}\left(\hat{x}_{1}-x_{1}\right),
\end{aligned}
$$

where $x_{3}=\left(-k_{\mathrm{sp}} / k_{l}^{2} J\right) x_{1}+C\left(x_{1}\right)+\bar{d}(t)$. In order to facilitate analysis, we also define $g_{i}(z)=l_{i} g(z)(i=1,2,3)$, and $g(z)$ is a nonlinear function. Hence, the ESO can be expressed as follows [29]:

$$
\begin{aligned}
& \dot{\widehat{x}}_{1}=\widehat{x}_{2}-l_{1} g_{1}\left(\widehat{x}_{1}-x_{1}\right), \\
& \dot{\bar{x}}_{2}=\widehat{x}_{3}-l_{2} g_{2}\left(\widehat{x}_{1}-x_{1}\right)+B u, \\
& \dot{\widehat{x}}_{3}=-l_{3} g_{3}\left(\widehat{x}_{1}-x_{1}\right) .
\end{aligned}
$$

Defining $\delta x_{1}=\widehat{x}_{1}-x_{1}, \delta x_{2}=\widehat{x}_{2}-x_{2}, \delta x_{3}=\widehat{x}_{3}-x_{3}$, then based on (8) and (13) we can obtain

$$
\begin{aligned}
& \delta \dot{x}_{1}=\delta x_{2}-l_{1} g_{1}\left(\delta x_{1}\right), \\
& \delta \dot{x}_{2}=\widehat{x}_{2}-l_{2} g_{2}\left(\delta x_{1}\right)+B u, \\
& \delta \dot{x}_{3}=-l_{3} g_{3}\left(\delta x_{1}\right)-\dot{x}_{3},
\end{aligned}
$$

where $\dot{x}_{3}$ is derivative of $x_{3}$.

Assume that $\dot{x}_{3}$ is bounded, and the nonlinear function $g(z)$ is smooth; that is, $g(0)=0$ and $\dot{g}(z) \neq 0$. Hence, (14) can be rewritten as follows:

$$
\begin{aligned}
& \delta \dot{x}_{1}=\delta x_{2}-l_{1} \dot{g}_{1}\left(\delta x_{1}\right) \delta x_{1}, \\
& \delta \dot{x}_{2}=\widehat{x}_{2}-l_{2} \dot{g}_{2}\left(\delta x_{1}\right) \delta x_{1}+B u, \\
& \delta \dot{x}_{3}=-l_{3} \dot{g}_{3}\left(\delta x_{1}\right) \delta x_{1}-\dot{x}_{3} .
\end{aligned}
$$

Suppose

$$
l_{i}=\frac{a_{i}}{\dot{g}\left(\delta x_{1}\right)} \quad(i=1,2,3) .
$$

Substituting (16) into (15), the state-space equation of (15) can be expressed as

$$
\left[\begin{array}{l}
\delta \dot{x}_{1} \\
\delta \dot{x}_{2} \\
\delta \dot{x}_{3}
\end{array}\right]=\left[\begin{array}{lll}
-a_{1} & 1 & 0 \\
-a_{2} & 0 & 1 \\
-a_{3} & 0 & 0
\end{array}\right]\left[\begin{array}{l}
\delta x_{1} \\
\delta x_{2} \\
\delta x_{3}
\end{array}\right]+\left[\begin{array}{c}
0 \\
0 \\
-1
\end{array}\right] \dot{x}_{3} .
$$




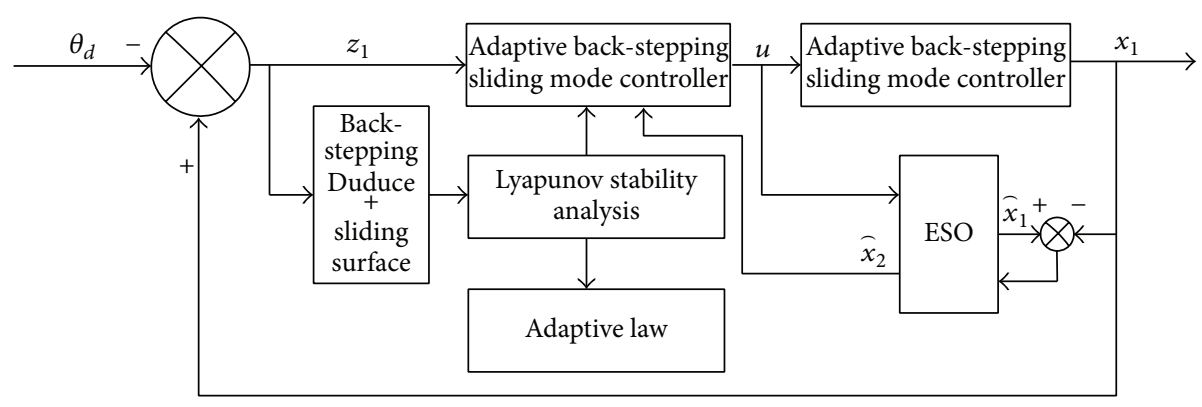

FIgURE 2: Control strategy.

Define

$$
\begin{gathered}
\mathbf{P}=\left[\begin{array}{ccc}
-a_{1} & 1 & 0 \\
-a_{2} & 0 & 1 \\
-a_{3} & 0 & 0
\end{array}\right], \quad \mathbf{E}=\left[\begin{array}{c}
0 \\
0 \\
-1
\end{array}\right], \\
\delta \mathbf{X}=\left(\begin{array}{lll}
\delta x_{1} & \delta x_{2} & \delta x_{3}
\end{array}\right)^{\mathbf{T}} .
\end{gathered}
$$

Then (17) can be rewritten as

$$
\delta \dot{\mathbf{X}}=\mathbf{P} \delta \mathbf{X}+\mathbf{E} \dot{x}_{3}
$$

It is shown from (19) that $l_{i}(i=1,2,3)$ can be determined by $a_{i}(i=1,2,3)$. Hence, we could choose appropriate parameters $a_{i}(i=1,2,3)$ to guarantee the closed-loop stability of system (19). follows:

Submitting (16) into (12), the ESO can be obtained as

$$
\begin{aligned}
& \dot{\vec{x}}_{1}=\widehat{x}_{2}-\frac{a_{1}}{\dot{g}\left(\widehat{x}_{1}-x_{1}\right)} g\left(\widehat{x}_{1}-x_{1}\right), \\
& \dot{\vec{x}}_{2}=\widehat{x}_{3}-\frac{a_{2}}{\dot{g}\left(\widehat{x}_{1}-x_{1}\right)} g\left(\widehat{x}_{1}-x_{1}\right)+B u, \\
& \dot{\vec{x}}_{3}=-\frac{a_{3}}{\dot{g}\left(\hat{x}_{1}-x_{1}\right)} g\left(\widehat{x}_{1}-x_{1}\right),
\end{aligned}
$$

where the nonlinear function $g(j)$ satisfies the following three conditions [29]:

(i) $g(j)$ is continuously differentiable;

(ii) $g(0)=0$;

(iii) $\mathrm{d} g(j) / \mathrm{d} j \neq 0$.

\section{Adaptive Back-Stepping SMC Design}

To overcome the disturbance and ensure the robustness of controller [32-34], we design the adaptive back-stepping controller with SMC for the ET system. Figure 2 illustrates the control strategy, where $\widehat{x}_{2}$ is the estimation of opening angle change for the ET.

The back-stepping technique consists of a step-by-step construction of a new system with state variables $z_{i}=x_{i}-x_{d, i}$, with $x_{d, i}$ being the desired value for state $x_{i}$. Let the desired ET angle be $\theta_{d}$, and we start by constructing the first state variable $z_{1}$ as the tacking error:

$$
z_{1}=x_{1}-\theta_{d}
$$

Then, we will design the second desired state $x_{d, 2}(t)$ such that the state $z_{1}$ satisfies $\dot{z}_{1}=-c_{1} z_{1}$ if $x_{2}(t)=x_{d, 2}(t)$, where $c_{1}$ is a positive constant. Then, it follows from (21) and (9) that $\dot{z}_{1}=$ $x_{2}-\dot{\theta}_{d}=x_{d, 2}-\dot{\theta}_{d}=-c_{1} z_{1}$. Hence, we have $x_{d, 2}=-c_{1} z_{1}+\dot{\theta}_{d}$, and the second system state variable $z_{2}$ is constructed as

$$
z_{2}=x_{2}-x_{d, 2}=x_{2}-\dot{\theta}_{d}+c_{1} z_{1} \text {. }
$$

The candidate Lyapunov function can be chosen as [35]

$$
V_{1}=\frac{1}{2} z_{1}^{2}
$$

Then, we have

$$
\dot{V}_{1}=z_{1} \dot{z}_{1}=z_{1}\left(x_{2}-\dot{\theta}_{d}\right)
$$

Based on the fact that $z_{2}=x_{2}-\dot{\theta}_{d}+c_{1} z_{1}$, we know that $\dot{z}_{1}=$ $x_{2}-\dot{\theta}_{d}=z_{2}-c_{1} z_{1}$; thus it is obtained that

$$
\dot{V}_{1}=z_{1} \dot{z}_{1}=z_{1} z_{2}-c_{1} z_{1}^{2} .
$$

To facilitate subsequent development, a sliding surface in terms of $z_{1}$ and $z_{2}$ is defined as follows:

$$
S=k_{1} z_{1}+z_{2}
$$

where $k_{1}>0$.

Remark 1. It is worthwhile to point out that, in general, the sliding mode surface is usually defined as $S=z_{2}$ for traditional back-stepping based SMC [36], for which it is required to guarantee that the system state converges to the sliding mode surface $S=z_{2}=0$ in finite time, and then, we can derive from (25) that $z_{1}$ will be stabilized to origin. However, unlike the traditional approach, we define the sliding surface as $S=k_{1} z_{1}+z_{2}$ in (26) other than $S=z_{2}$, and it is shown in the subsequent Theorems 2 and 3 that $z_{1}(t), z_{2}(t)$, and $S(t)$ will asymptotically converge to zero simultaneously, which relaxes the finite-time requirement for the sliding surface in the traditional design. 
Inspired by the Lyapunov-based control design methods, a controller with the capability of disturbance rejection and strong robustness is designed as follows:

$$
\begin{aligned}
u=\frac{1}{B}[ & -k_{1}\left(z_{2}-c_{1} z_{1}\right)-A \mathbf{x}-c_{1} \dot{z}_{1}+\ddot{\theta}_{d}-\bar{F} \operatorname{sgn}(S) \\
& -\kappa(S+\eta \operatorname{sgn}(S))],
\end{aligned}
$$

where $\kappa>0, \eta>0$.

Theorem 2. With the proposed controller in (27), if the following condition is satisfied:

$$
|Q|>0,
$$

with

$$
Q=\left[\begin{array}{cc}
c_{1}+\kappa k_{1}^{2} & \kappa k_{1}-\frac{1}{2} \\
\kappa k_{1}-\frac{1}{2} & \kappa
\end{array}\right] .
$$

Then the closed-loop system is Lyapunov stable in the sense that

$$
\lim _{t \rightarrow \infty} z_{1}(t)=0, \quad \lim _{t \rightarrow \infty} z_{2}(t)=0, \quad \lim _{t \rightarrow \infty} S(t)=0 .
$$

Proof. Based on (23), a candidate Lyapunov function can be chosen as [37]

$$
V_{2}=V_{1}+\frac{1}{2} S^{2}
$$

Then

$$
\begin{aligned}
\dot{V}_{2}= & \dot{V}_{1}+S \dot{S}=z_{1} z_{2}-c_{1} z_{1}^{2}+S\left(k_{1} \dot{z}_{1}+\dot{z}_{2}\right) \\
= & z_{1} z_{2}-c_{1} z_{1}^{2} \\
& +S\left(k_{1}\left(z_{2}-c_{1} z_{1}\right)+A \mathbf{x}+B u+F-\ddot{\theta}_{d}+c_{1} \dot{z}_{1}\right) .
\end{aligned}
$$

Based on (32), let

$$
\begin{aligned}
u=\frac{1}{B}[ & -k_{1}\left(z_{2}-c_{1} z_{1}\right)-A \mathbf{x}-c_{1} \dot{z}_{1}+\ddot{\theta}_{d}-\bar{F} \operatorname{sgn}(S) \\
& -\kappa(S+\eta \operatorname{sgn}(S))],
\end{aligned}
$$

where $\kappa>0, \eta>0$; then

$$
\begin{aligned}
\dot{V}_{2}= & \dot{V}_{1}+S \dot{S} \\
= & z_{1} z_{2}-c_{1} z_{1}^{2} \\
& +S\left(k_{1}\left(z_{2}-c_{1} z_{1}\right)+A \mathbf{x}+B u+F-\ddot{\theta}_{d}+c_{1} \dot{z}_{1}\right) \\
& z_{1} z_{2}-c_{1} z_{1}^{2}-\kappa S^{2}-\kappa \eta|S|+F S-\bar{F}|S| \\
\leq & -c_{1} z_{1}^{2}+z_{1} z_{2}-\kappa S^{2}-\kappa \eta|S| .
\end{aligned}
$$

Let

$$
Q=\left[\begin{array}{cc}
c_{1}+\kappa k_{1}^{2} & \kappa k_{1}-\frac{1}{2} \\
\kappa k_{1}-\frac{1}{2} & \kappa
\end{array}\right] .
$$

Hence

$$
\begin{aligned}
z^{\mathrm{T}} Q z & =\left[\begin{array}{ll}
z_{1} & z_{2}
\end{array}\right]\left[\begin{array}{cc}
c_{1}+\kappa k_{1}^{2} & \kappa k_{1}-\frac{1}{2} \\
\kappa k_{1}-\frac{1}{2} & \kappa
\end{array}\right]\left[\begin{array}{l}
z_{1} \\
z_{2}
\end{array}\right] \\
& =c_{1} z_{1}^{2}-z_{1} z_{2}+\kappa k_{1}^{2} z_{1}^{2}+2 \kappa k_{1} z_{1} z_{2}+\kappa z_{2}^{2} \\
& =c_{1} z_{1}^{2}-z_{1} z_{2}+\kappa S^{2}
\end{aligned}
$$

where $z^{\mathbf{T}}=\left[\begin{array}{ll}z_{1} & z_{2}\end{array}\right]$. Consider

$$
|Q|=\kappa\left(c_{1}+\kappa k_{1}^{2}\right)-\left(\kappa k_{1}-\frac{1}{2}\right)^{2}=\kappa\left(c_{1}+\kappa k_{1}\right)-\frac{1}{4} .
$$

If $\kappa, c_{1}$, and $k_{1}$ are designed reasonably to ensure $|Q|>0$, then $Q$ is a positive definite matrix. Consequently,

$$
\dot{V}_{2} \leq-z^{\mathrm{T}} \mathrm{Q} z-\kappa \eta|S| \leq 0 .
$$

According to $\dot{V}_{2} \leq 0$, we know that $V_{2}$ is a nonincreasing function when $t \in[0, \infty)$, so $V_{2}(t) \leq V_{2}(0)<\infty$.

Since

$$
\begin{aligned}
\ddot{V}_{2}= & \dot{z}_{1} z_{2}+z_{1} \dot{z}_{2}-2 c_{1} z_{1} \dot{z}_{1}-\kappa S \dot{S}-\kappa \eta \dot{S} \operatorname{sgn}(S) \\
& +F \dot{S}-\bar{F} \dot{S} \operatorname{sgn}(S) .
\end{aligned}
$$

Based on (21), (26), and (32), we know that $z_{1}(t), z_{2}(t)$, and $S(t)$ are bounded when $t \geq 0$. Since $\dot{z}_{1}(t)=z_{2}-c_{1} z_{1}$, we know that $\dot{z}_{1}(t) \in \mathscr{L}_{\infty}$. Assuming that $\theta_{d}, \dot{\theta}_{d}, \ddot{\theta}_{d} \in \mathscr{L}_{\infty}$, it is known from $\dot{z}_{2}(t)=\dot{x}_{2}-\ddot{\theta}_{d}-c_{1} \dot{z}_{1}$ that $\dot{z}_{2}(t) \in \mathscr{L}_{\infty}$. Furthermore, based on (39), we know that $\dot{V}_{2}$ is uniformly continuous because $\ddot{V}_{2} \in \mathscr{L}_{\infty}$.

In addition, we have

$$
\int_{0}^{\infty}\left|\dot{V}_{2}\right| \mathrm{d} t=\left|V_{2}(\infty)\right|-\left|V_{2}(0)\right|<\infty
$$

According to (40), we know that $\dot{V}_{2} \in \mathscr{L}_{2}$. Hence, we know that $\lim _{t \rightarrow \infty} \dot{V}_{2}=0$ based on Barbalat's Lemma [38]. Moreover, we know from $\dot{V}_{2} \leq-z^{\mathrm{T}} \mathrm{Q} z-\kappa \eta|S| \leq 0$ that $\lim _{t \rightarrow \infty} \dot{V}_{2}(t) \leq \lim _{t \rightarrow \infty}\left(-z^{\mathrm{T}} Q z-\kappa \eta|S|\right) \leq 0$; thus we have $\lim _{t \rightarrow \infty}\left(z^{\mathrm{T}} Q z+\kappa \eta|S|\right)=0$. Consequently, we have $\lim _{t \rightarrow \infty} z_{1}(t)=0, \lim _{t \rightarrow \infty} z_{2}(t)=0, \lim _{t \rightarrow \infty} S(t)=0$.

Furthermore, if the parametric uncertainties in ET are considered, an adaptive controller is designed as follows:

$$
\begin{aligned}
u=\frac{1}{B}\left[-k_{1}\right. & \left(z_{2}-c_{1} z_{1}\right)-A \mathbf{x}-\widehat{F}+\ddot{\theta}_{d}-c_{1} \dot{z}_{1} \\
- & \kappa(S+\eta \operatorname{sgn}(S))] \\
=\frac{k_{l} J R_{a}}{k_{t} k_{\mathrm{ch}}}[ & \frac{-\left(\pi k_{\mathrm{sp}}+2 k k_{\mathrm{pre}}\right)}{\pi k_{l}^{2} J} x_{1}-\widehat{F}+\frac{k_{l}^{2} k_{t} k_{v}+k_{f} R_{a}}{k_{l}^{2} J R_{a}} x_{2} \\
& +\ddot{\theta}_{d}-\left(k_{1}+c_{1}\right) x_{2}+k_{1} c_{1} z_{1}+\left(k_{1}+c_{1}\right) \dot{\theta}_{d} \\
& -\kappa(S+\eta \operatorname{sgn}(S))]
\end{aligned}
$$


where $\widehat{F}$ is the estimation of $F$, and the parameter updating law is designed as

$$
\dot{\widehat{F}}=\lambda S=\lambda\left[\left(k_{1}+c_{1}\right)\left(x_{1}-\theta_{d}\right)+x_{2}-\dot{\theta}_{d}\right] .
$$

Theorem 3. With the proposed adaptive controller in (41) and the parameter estimation law in (42), if $|Q|>0$, with

$$
Q=\left[\begin{array}{cc}
c_{1}+\kappa k_{1}^{2} & \kappa k_{1}-\frac{1}{2} \\
\kappa k_{1}-\frac{1}{2} & \kappa
\end{array}\right],
$$

then the closed-loop system is stable in the sense that

$$
\lim _{t \rightarrow \infty} z_{1}(t)=0, \quad \lim _{t \rightarrow \infty} z_{2}(t)=0, \quad \lim _{t \rightarrow \infty} S(t)=0 .
$$

Proof. Firstly, we assume that the parametric uncertainties and external disturbance change slowly; then $\dot{F}=0$. To design the controller with adaptive capability of parametric uncertainties, the candidate Lyapunov function is defined as follows [37]:

$$
V_{3}=V_{2}+\frac{1}{2 \lambda} \widetilde{F}^{2}
$$

where $\widetilde{F}=F-\widehat{F}$, and $\widehat{F}$ is the estimation of $F, \lambda>0$. Then

$$
\begin{aligned}
\dot{V}_{3}= & \dot{V}_{2}-\frac{1}{\lambda} \widetilde{\hat{F}} \dot{\vec{F}} \\
= & z_{1} z_{2}-c_{1} z_{1}^{2} \\
& +S\left[k_{1}\left(z_{2}-c_{1} z_{1}\right)+A \mathbf{x}+B u+\widehat{F}-\ddot{\theta}_{d}+c_{1} \dot{z}_{1}\right] \\
& -\frac{1}{\lambda} \widetilde{F}(\dot{\widehat{F}}-\lambda S) .
\end{aligned}
$$

Based on (46), we let

$$
\begin{aligned}
u=\frac{1}{B}[ & -k_{1}\left(z_{2}-c_{1} z_{1}\right)-A \mathbf{x}-\widehat{F}+\ddot{\theta}_{d}-c_{1} \dot{z}_{1} \\
- & \kappa(S+\eta \operatorname{sgn}(S))] \\
=\frac{k_{l} J R_{a}}{k_{t} k_{\mathrm{ch}}}[ & \frac{-\left(\pi k_{\mathrm{sp}}+2 k k_{\mathrm{pre}}\right)}{\pi k_{l}^{2} J} x_{1}-\widehat{F}+\frac{k_{l}^{2} k_{t} k_{v}+k_{f} R_{a}}{k_{l}^{2} J R_{a}} x_{2} \\
& +\ddot{\theta}_{d}-\left(k_{1}+c_{1}\right) x_{2}+k_{1} c_{1} z_{1}+\left(k_{1}+c_{1}\right) \dot{\theta}_{d} \\
& -\kappa(S+\eta \operatorname{sgn}(S))], \\
\dot{\widehat{F}}= & \lambda S=\lambda\left[\left(k_{1}+c_{1}\right)\left(x_{1}-\theta_{d}\right)+x_{2}-\dot{\theta}_{d}\right] .
\end{aligned}
$$

Hence, substituting (47) into (46), we have

$$
\dot{V}_{3}=\dot{V}_{2}-\frac{1}{\lambda} \widetilde{F} \dot{\vec{F}}=z_{1} z_{2}-c_{1} z_{1}^{2}-\kappa S^{2}-\kappa \eta|S| .
$$

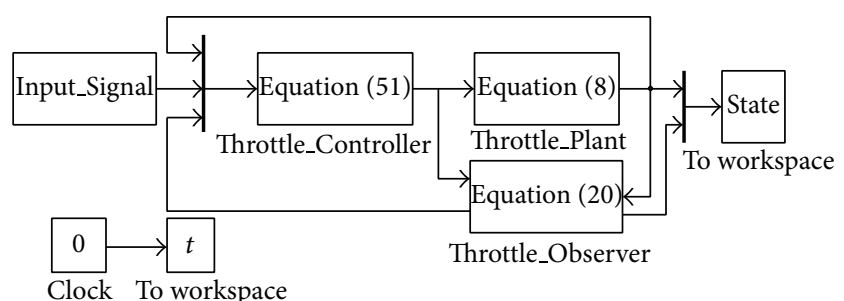

FIGURE 3: Simulink main program.

According to (36), we can rewrite (48) as

$$
\dot{V}_{3} \leq-z^{\mathrm{T}} \mathrm{Q} z-\kappa \eta|S| .
$$

If $Q$ is a positive definite matrix, then $\dot{V}_{3} \leq 0$. Hence, the proposed adaptive controller is Lyapunov stable.

Similar to the proof of Theorem 2, then we can use Barbalat's Lemma to obtain that [38]

$$
\lim _{t \rightarrow \infty} z_{1}(t)=0, \quad \lim _{t \rightarrow \infty} z_{2}(t)=0, \quad \lim _{t \rightarrow \infty} S(t)=0 .
$$

Based on the above discussion, if the immeasurable variable $x_{2}$ in (47) is replaced with the estimation value $\widehat{x}_{2}$, we can obtain the back-stepping SMC incorporating the proposed ESO as follows:

$$
\begin{aligned}
u=\frac{k_{l} J R_{a}}{k_{t} k_{\mathrm{ch}}}[ & \frac{-\left(\pi k_{\mathrm{sp}}+2 k k_{\mathrm{pre}}\right)}{\pi k_{l}^{2} J} x_{1}+\frac{k_{l}^{2} k_{t} k_{v}+k_{f} R_{a}}{k_{l}^{2} J R_{a}} \widehat{x}_{2}-\widehat{F} \\
& +\ddot{\theta}_{d}-\left(k_{1}+c_{1}\right) \widehat{x}_{2}+\left(k_{1}+c_{1}\right) \dot{\theta}_{d}+k_{1} c_{1} z_{1} \\
& -\kappa(S+\eta \operatorname{sgn}(S))], \\
\dot{\vec{F}}= & \lambda S=\lambda\left[\left(k_{1}+c_{1}\right)\left(x_{1}-\theta_{d}\right)+\widehat{x}_{2}-\dot{\theta}_{d}\right] .
\end{aligned}
$$

\section{Numerical Experiments}

5.1. Simulations. In order to verify the effectiveness of the proposed controller, the simulation of ETC is conducted under the Matlab/Simulink platform based on the dynamic characteristics of ET valve. In addition, we choose $g(j)=$ $\left(1-e^{-j}\right) /\left(1+e^{-j}\right)$. The whole Simulink main program is shown in Figure 3 and the basic parameter configuration of ET is listed in Table 1.

According to the requirement of ETC in engineering applications given in [12], the reference inputs are chosen as the step and sine signals, respectively. Figure 4 depicts the signal tracking results using the step reference signal when the desired throttle opening is $60^{\circ}$. Figure 4 shows that the position of ET is able to track the reference signal without overshoot within $100 \mathrm{~ms}$, while the tracking results with 
TABLE 1: Basic parameter comfiguration of ET.

\begin{tabular}{lcc}
\hline Parameters & Value & Units \\
\hline$\theta_{0}$ & 2 & $\mathrm{deg}$ \\
$k_{l}$ & 16.95 & - \\
$k_{t}$ & 0.016 & $\mathrm{~N} \cdot \mathrm{m} / \mathrm{A}$ \\
$k_{\text {pre }}$ & 0.107 & $\mathrm{~N} \cdot \mathrm{m}$ \\
$R_{a}$ & 2.8 & $\Omega$ \\
$J$ & $4 \times 10^{-6}$ & $\mathrm{~kg} \cdot \mathrm{m}^{2}$ \\
$k_{t f}$ & 0.0048 & $\mathrm{~N} \cdot \mathrm{m}$ \\
$k_{\mathrm{ch}}$ & 2.4 & - \\
$k_{v}$ & 0.016 & $\mathrm{~V} \cdot \mathrm{s} / \mathrm{rad}$ \\
$k_{f}$ & $4 \times 10^{-4}$ & $\mathrm{~N} \cdot \mathrm{m} \cdot \mathrm{s} / \mathrm{rad}$ \\
$k_{\mathrm{sp}}$ & 0.0247 & $\mathrm{~N} \cdot \mathrm{m} / \mathrm{rad}$ \\
\hline
\end{tabular}



Figure 4: Step tracking response.

the sine reference signal are shown in Figure 5. From Figures 4 and 5 , the results show that the proposed controller can satisfy the ET tracking control requirement in [12] with the step and sine reference signals.

As foregoing discussion, those parameters $\left(k_{t}, k_{t f}, k_{\mathrm{sp}}\right)$ are designed using Lyapunov techniques. Figure 6 is the step response of ETC with parametric uncertainties when desired throttle opening is $60^{\circ}$ and the parameters $\Delta k_{t}= \pm 0.0048$, $\Delta k_{t f}= \pm 0.0014, \Delta k_{\mathrm{sp}}= \pm 0.0074$. Figure 6 shows that the settling time of ETC is less than $100 \mathrm{~ms}$. Figure 6 also shows that the steady-state error of ETC tends to zero. Figure 7 is the adaptive estimation value of the total uncertainty $F$. In addition, the results form Figure 6 show that the proposed controller has a better robustness compared with Figure 4 .

The discussion mentioned above demonstrates that the proposed controller has strong robustness with respect to parametric uncertainties. That is to say, a stable vehicle speed can be guaranteed since the adaptive controller can quickly adjust the opening angle of ET valve when an external disturbance occurs.

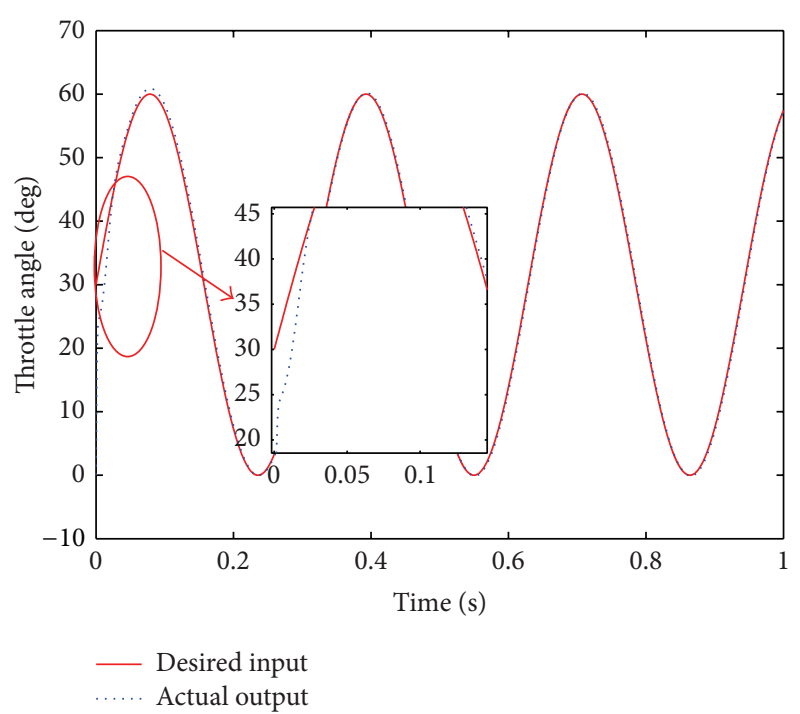

FIGURE 5: Sine tracking response.
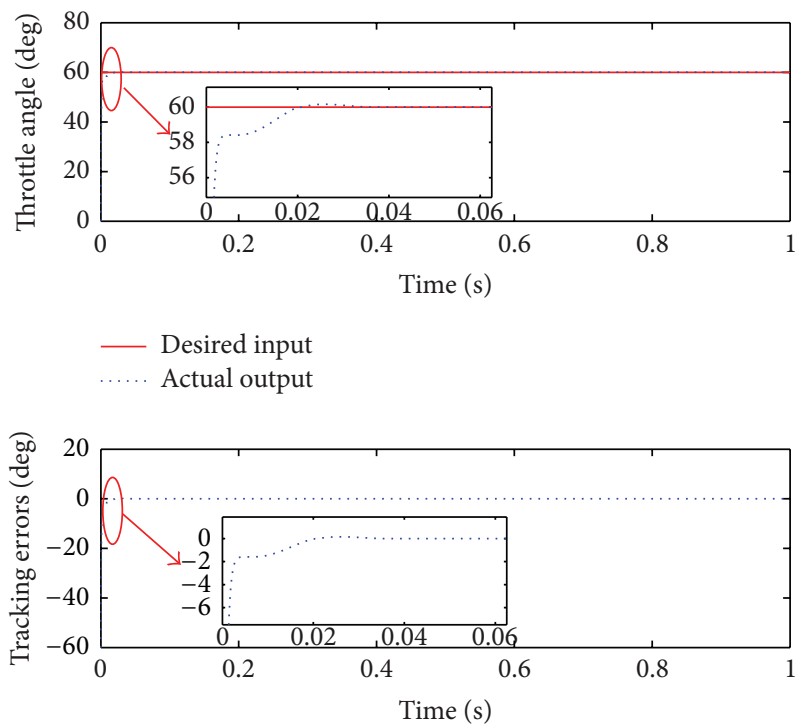

FIGURE 6: Step tracking response of parameters changes.

In practical application, the mutation of throttle opening is inevitable, which has important influence on vehicle acceleration/deceleration. Furthermore, traffic congestion will lead to the stop-and-go phenomenon in traffic flow, further resulting in the vehicle speed change. Hence, ET should have good responsiveness capability to track the change.

Therefore, it is significant to conduct analysis on the controller performance under the condition of input signal mutation. Moreover, the nonlinear spring does not allow opening angles below $5^{\circ}$ and above $80^{\circ}$ [20]; the experiment under the minimum and maximum values of square reference signal is set as $10^{\circ}$ and $60^{\circ}$, respectively, as shown in Figure 8. Figure 8 shows that the proposed controller can track the small values accurately (the important condition of idle speed control), so does the large values (the essential condition of 
TABLE 2: Controller performance comparison.

\begin{tabular}{lccc}
\hline Control methods & Setting time & Steady-state errors under parameter change & Overshoot \\
\hline Back-stepping control in [4] & $<140 \mathrm{~ms}$ & $<2^{\circ}$ & a little \\
Controller of this present paper & $<100 \mathrm{~ms}$ & $<0.1^{\circ}$ & little \\
\hline
\end{tabular}

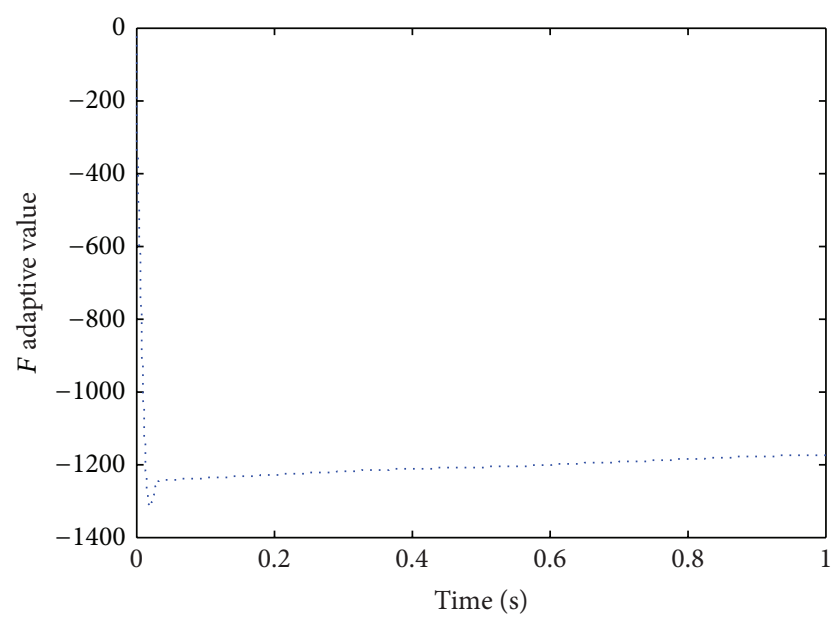

Figure 7: Estimation of $F$.
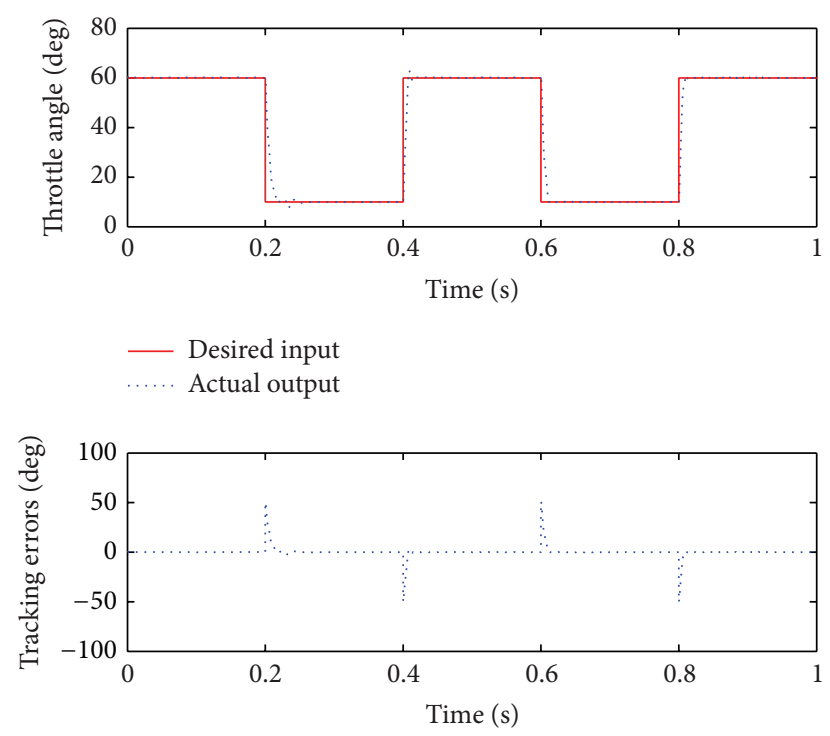

FIGURE 8: Square wave tracking response.

vehicle acceleration). In addition, the settling time is less than required $100 \mathrm{~ms}$. On the other hand, Figure 8 also shows that the steady-state errors approximate 0 , which illustrates that the proposed controller can satisfy the requirement of ETC. Hence, the results from this simulation show that the designed controller also has a good control performance under square wave input signal. It also implies that the vehicle in the platoon can follow the preceding vehicles with safe space headway and safe speed via ETC when the stop-andgo phenomenon emerges.

5.2. Performance Comparison. Compared with the literature [4], this study considers not only the external disturbance, but also the parametric uncertainties and the torque caused by the air flow. Then the adaptive law is designed using the Lyapunov techniques. Finally, the experiment is conducted using simulation and the comparison results are summarized in Table 2. Table 2 shows that the proposed adaptive backstepping SMC has better control performance than the backstepping controller in [4] in terms of the settling time, steadystate error, and the overshoot.

5.3. Simulated Experiment. In this section, we incorporate the ET controller with mean value modeling of spark ignition engine under the conditions of pressing the accelerator pedal and easing it off [39]. The schematic block diagram of main simulation is shown in Figure 9. Figure 10 shows the throttle opening angle tracking performance. It can be seen that the proposed controller can track the desired input signal effectively. Figures 11, 12, and 13 show the manifold pressure, engine speed, and throttle airflow, respectively. The results show that the proposed controller can control the engine accurately via ETC.

\section{Conclusions}

To improve the accuracy of the information for ETC under V2V communications, an ESO based adaptive back-stepping SMC is proposed based on the Lyapunov theory, in the presence of high nonlinearity of ET and immeasurable signals for throttle opening angle change. In addition, with the designed adaptive law, strong robustness to parametric uncertainties and external disturbance can be achieved. Simulation results show that the proposed controller can track the desired reference input signal fast and accurately with strong robustness to uncertainties and disturbances.

\section{Conflict of Interests}

The authors declare that there is no conflict of interests regarding the publication of this paper.

\section{Acknowledgments}

This work is jointly supported by the National Natural Science Foundation of China (Grant no. 61304197), the Scientific and 


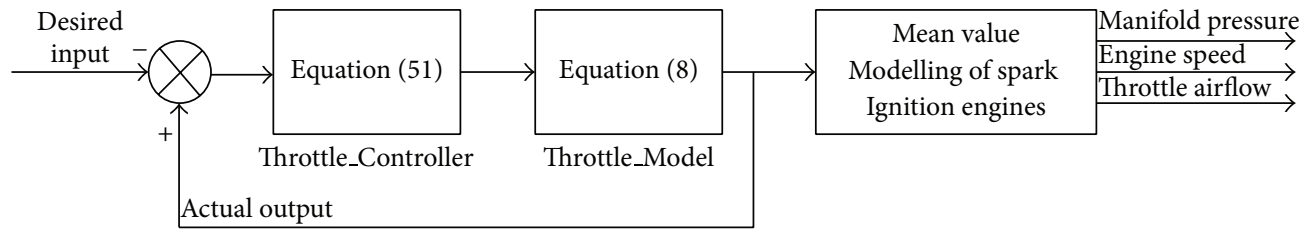

FIGURE 9: Schematic block diagram of main simulation.
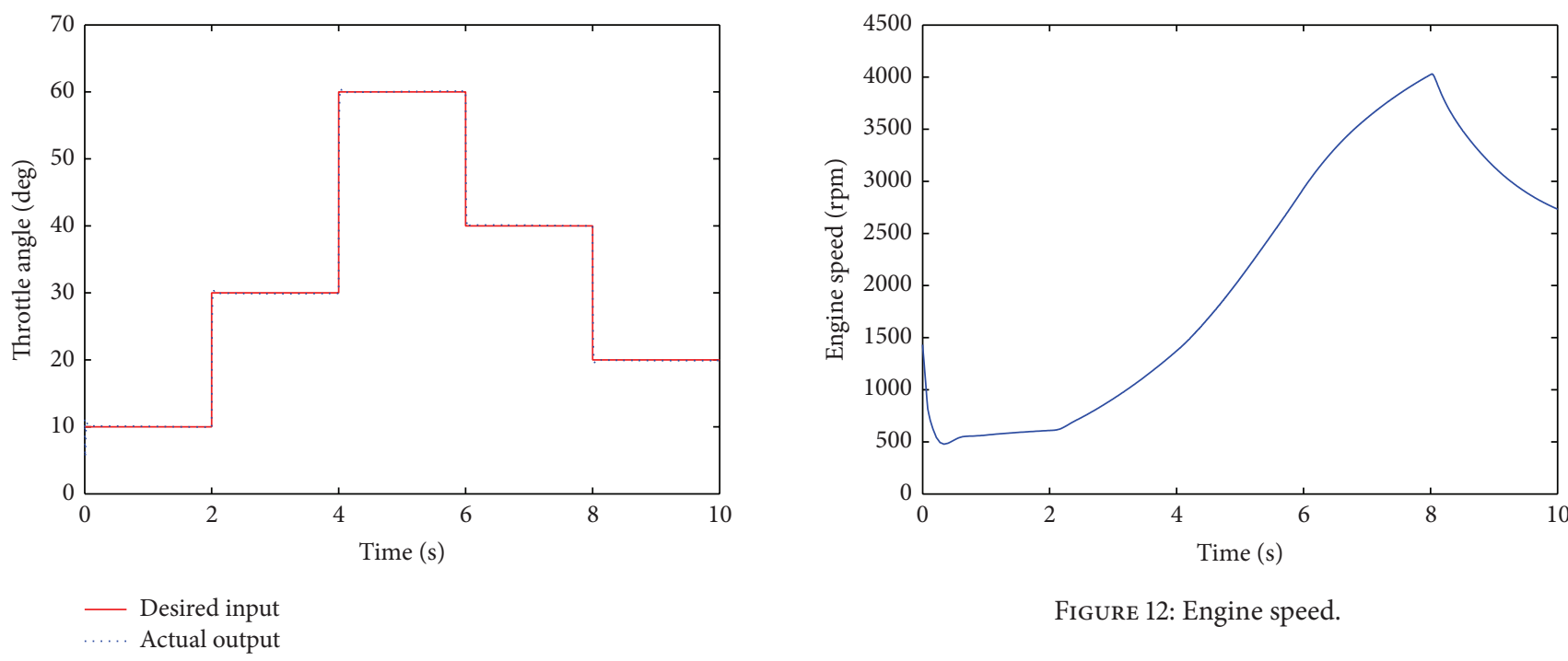

Figure 12: Engine speed.

FIGURE 10: Throttle opening angle.
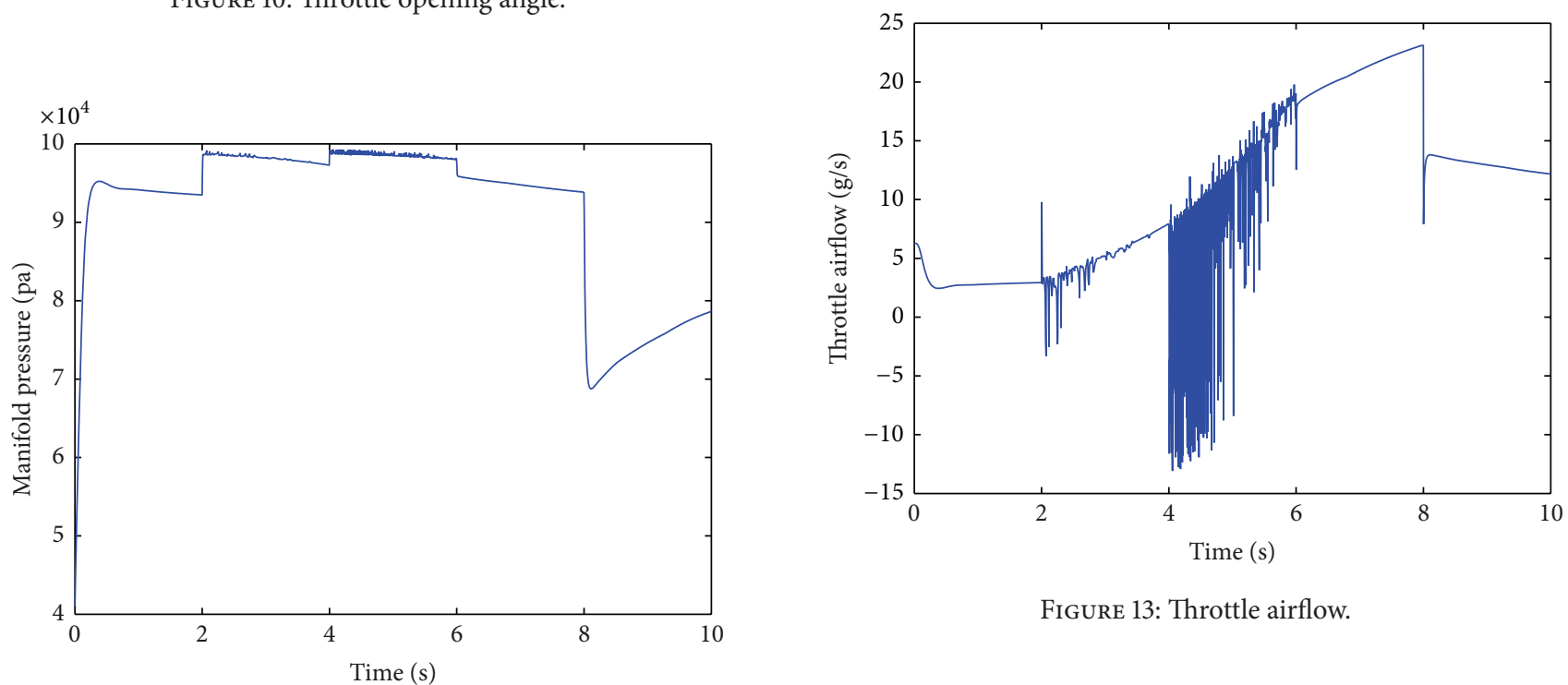

FIgURE 13: Throttle airflow.

FIGURE 11: Manifold pressure.

Technological Talents of Chongqing (Grant no. cstc2014kjrcqnrc30002), the Key Project of Application and Development of Chongqing (Grant no. cstc2014yykfB40001), the Nature Science Funds of Education Committee of Chongqing (Grant no. KJ130506), Natural Science Funds of Chongqing (Grant nos. cstc2014jcyjA60003 and cstc2012jjA40035), and Natural

Science Funds of CQUPT (Grant nos. A2012-78 and A201327). The authors would like to express their gratitude to Dr. Hongchun Qu and Dr. Xiaoming Tang from Chongqing University of Posts and Telecommunications for their good discussions on the paper preparation.

\section{References}

[1] V. Milanes, S. E. Shladover, J. Spring, C. Nowakowski, H. Kawazoe, and M. Nakamura, "Cooperative adaptive cruise 
control in real traffic situations," IEEE Transactions on Intelligent Transportation Systems, vol. 15, no. 1, pp. 296-305, 2014.

[2] D.-H. Sun, Y.-F. Li, W.-N. Liu, M. Zhao, and X.-Y. Liao, "Re search summary on transportation cyber physical systems and the challenging technologies," China Journal of Highway and Transport, vol. 26, no. 1, pp. 144-154, 2013.

[3] L. Li, D. Wen, and D. Yao, "A survey of traffic control with vehicular communications," IEEE Transactions on Intelligent Transportation Systems, vol. 15, no. 1, pp. 425-432, 2014.

[4] Y. F. Hu, C. Li, J. Li, H. Y. Guo, P. Y. Sun, and H. Chen, "Observerbased output feedback control of electronic throttles," Acta Automatica Sinica, vol. 37, no. 6, pp. 746-754, 2011.

[5] P. Ioannou and $\mathrm{Z}$. Xu, "Throttle and brake control system for automatic vehicle following," Journal of Intelligent Transportation Systems, vol. 1, no. 4, pp. 345-377, 1994.

[6] Y. Li and D. Sun, "Microscopic car-following model for the traffic flow: the state of the art," Journal of Control Theory and Applications, vol. 10, no. 2, pp. 133-143, 2012.

[7] T. Tang, W. Shi, H. Shang, and Y. Wang, "A new car-following model with consideration of inter-vehicle communication," Nonlinear Dynamics, vol. 76, no. 4, pp. 2017-2023, 2014.

[8] J. Ploeg, N. Van De Wouw, and H. Nijmeijer, "Lp string stability of cascaded systems: application to vehicle platooning," IEEE Transactions on Control Systems Technology, vol. 22, no. 2, pp. 786-793, 2014.

[9] W. Wang, S. S. Liao, X. Li, and J. S. Ren, "The process of information propagation along a traffic stream through intervehicle communication," IEEE Transactions on Intelligent Transportation Systems, vol. 15, no. 1, pp. 345-354, 2014.

[10] L. Xiao and F. Gao, "Practical string stability of platoon of adaptive cruise control vehicles," IEEE Transactions on Intelligent Transportation Systems, vol. 12, no. 4, pp. 1184-1194, 2011.

[11] X. F. Yuan, Y. N. Wang, L. H. Wu, X. Z. Zhang, and W. Sun, "Neural network based self-learning control strategy for electronic throttle valve," IEEE Transactions on Vehicular Technology, vol. 59, no. 8, pp. 3757-3765, 2010.

[12] J. Deur, D. Pavković, N. Perić, M. Jansz, and D. Hrovat, “An electronic throttle control strategy including compensation of friction and limp-home effects," IEEE Transactions on Industry Applications, vol. 40, no. 3, pp. 821-834, 2004.

[13] D. Pavković, J. Deur, M. Jansz, and N. Perić, "Adaptive control of automotive electronic throttle," Control Engineering Practice, vol. 14, no. 2, pp. 121-136, 2006.

[14] X. Yuan and Y. Wang, "A novel electronic-throttle-valve controller based on approximate model method," IEEE Transactions on Industrial Electronics, vol. 56, no. 3, pp. 883-890, 2009.

[15] M. Vašak, M. Baotić, M. Morari, I. Petrović, and N. Perić, "Constrained optimal control of an electronic throttle," International Journal of Control, vol. 79, no. 5, pp. 465-478, 2006.

[16] M. Vašak, M. Baotić, I. Petrović, and N. Perić, "Hybrid theorybased time-optimal control of an electronic throttle," IEEE Transactions on Industrial Electronics, vol. 54, no. 3, pp. 14831494, 2007.

[17] D. Kim, H. Peng, S. Bai, and J. M. Maguire, "Control of integrated powertrain with electronic throttle and automatic transmission," IEEE Transactions on Control Systems Technology, vol. 15, no. 3, pp. 474-482, 2007.

[18] K. Nakano, U. Sawut, K. Higuchi, and Y. Okajima, "Modelling and observer-based sliding-mode control of electronic throttle system," ECTI Transactions on Electrical Engineering, Electronics, and Communications, vol. 4, no. 1, pp. 22-28, 2006.
[19] M. Horn and M. Reichhartinger, "Second-order sliding mode control of electronic throttle valves," in Proceedings of the IEEE 10th International Workshop on Variable Structure Systems (VSS '08), pp. 280-284, IEEE, Antalya, Turkey, June 2008.

[20] Y. D. Pan, Ü. Özguner, and O. H. Dağci, "Variable-structure control of electronic throttle valves," IEEE Transactions on Industrial Electronics, vol. 55, no. 11, pp. 3899-3907, 2008.

[21] R. Bai and S. Tong, "Adaptive backstepping sliding-mode control of the electronic throttle system in modern automobiles," Mathematical Problems in Engineering, vol. 2014, Article ID 383064, 8 pages, 2014.

[22] X. Yuan, Y. Wang, and L. Wu, "SVM-based approximate model control for electronic throttle valve," IEEE Transactions on Vehicular Technology, vol. 57, no. 5, pp. 2747-2756, 2008.

[23] M. Barić, I. Petrović, and N. Perić, "Neural network-based sliding mode control of electronic throttle," Engineering Applications of Artificial Intelligence, vol. 18, no. 8, pp. 951-961, 2005.

[24] M. Nentwig and P. Mercorelli, "Throttle valve control using an inverse local linear model tree based on a Fuzzy neural network," in Proceedings of the 7th IEEE International Conference on Cybernetic Intelligent Systems (CIS '08), pp. 1-6, London, UK, September 2008.

[25] M. Barić, I. Petrović, and N. Perić, "Neural network based sliding mode controller for a class of linear systems with unmatched uncertainties," in Proceedings of the 41st IEEE Conference on Decision and Control, vol. 1, pp. 967-972, Las Vegas, Nev, USA, December 2002.

[26] W. Sheng and Y. Bao, "Fruit fly optimization algorithm based fractional order fuzzy-PID controller for electronic throttle," Nonlinear Dynamics, vol. 73, no. 1-2, pp. 611-619, 2013.

[27] C.-H. Wang and D.-Y. Huang, "A new intelligent fuzzy controller for nonlinear hysteretic electronic throttle in modern intelligent automobiles," IEEE Transactions on Industrial Electronics, vol. 60, no. 6, pp. 2332-2345, 2013.

[28] A. K. Yadav and P. Gaur, "Robust adaptive speed control of uncertain hybrid electric vehicle using electronic throttle control with varying road grade," Nonlinear Dynamics, vol. 76, no. 1, pp. 305-321, 2014.

[29] Z. J. Kang and X. Y. Chen, "A design method of nonlinear extension state observer," Electric Machines and Control, vol. 5, no. 3, pp. 199-203, 2001.

[30] A. A. Godbole, J. P. Kolhe, and S. E. Talole, "Performance analysis of generalized extended state observer in tackling sinusoidal disturbances," IEEE Transactions on Control Systems Technology, vol. 21, no. 6, pp. 2212-2223, 2013.

[31] Z. Gao, X. Dai, T. Breikin, and H. Wang, "Novel parameter identification by using a high-gain observer with application to a gas turbine engine," IEEE Transactions on Industrial Informatics, vol. 4, no. 4, pp. 271-279, 2008.

[32] M. Morawiec, "The adaptive backstepping control of permanent magnet synchronous motor supplied by current source inverter," IEEE Transactions on Industrial Informatics, vol. 9, no. 2, pp. 1047-1055, 2013.

[33] J. R. Dominguez, A. Navarrete, M. A. Meza, A. G. Loukianov, and J. Cañedo, "Digital sliding-mode sensorless control for surface-mounted PMSM," IEEE Transactions on Industrial Informatics, vol. 10, no. 1, pp. 137-151, 2014.

[34] D. Zhao, T. Zou, S. Li, and Q. Zhu, "Adaptive backstepping sliding mode control for leader-follower multi-agent systems," IET Control Theory \& Applications, vol. 6, no. 8, pp. 1109-1117, 2012. 
[35] Y. C. Fang, P. C. Wang, N. Sun, and Y. C. Zhang, "Dynamics analysis and nonlinear control of an offshore boom crane," IEEE Transactions on Industrial Electronics, vol. 61, no. 1, pp. 414-427, 2014.

[36] Y. Xia, Z. Zhu, and M. Fu, "Back-stepping sliding mode control for missile systems based on an extended state observer," IET Control Theory \& Applications, vol. 5, no. 1, pp. 93-102, 2011.

[37] N. Sun, Y. C. Fang, and H. Chen, "A new antiswing control method for underactuated cranes with unmodeled uncertainties: theoretical design and hardware experiments," IEEE Transactions on Industrial Electronics, vol. 62, no. 1, pp. 453-465, 2015.

[38] X. Zhang, Y. Fang, and N. Sun, "Minimum-time trajectory planning for underactuated overhead crane systems with state and control constraints," IEEE Transactions on Industrial Electronics, vol. 61, no. 12, pp. 6915-6925, 2014.

[39] E. Hendricks and S. C. Sorenson, "Mean value modelling of spark ignition engines," SAE Technical Paper 900616, 1990. 


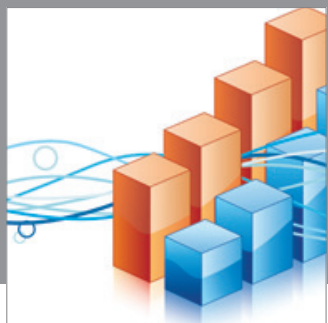

Advances in

Operations Research

mansans

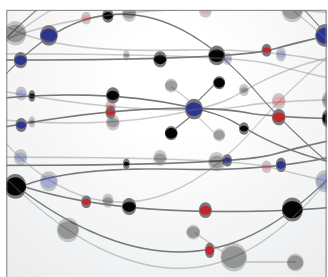

The Scientific World Journal
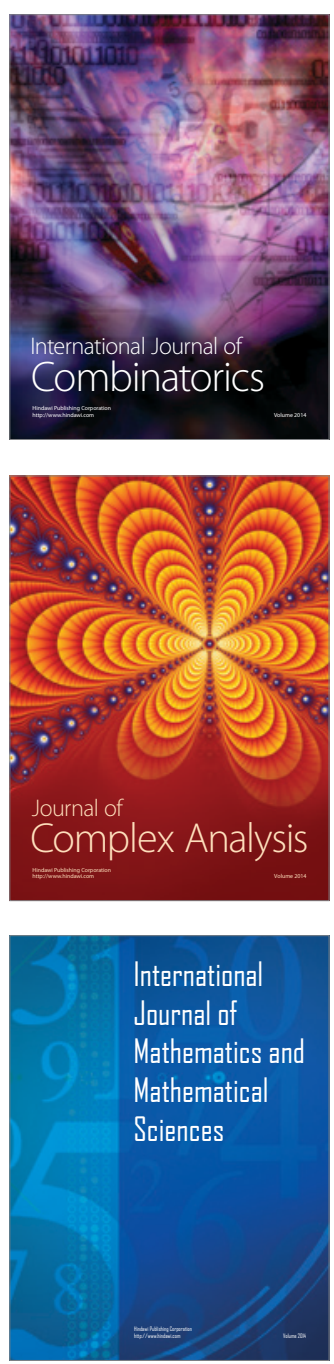
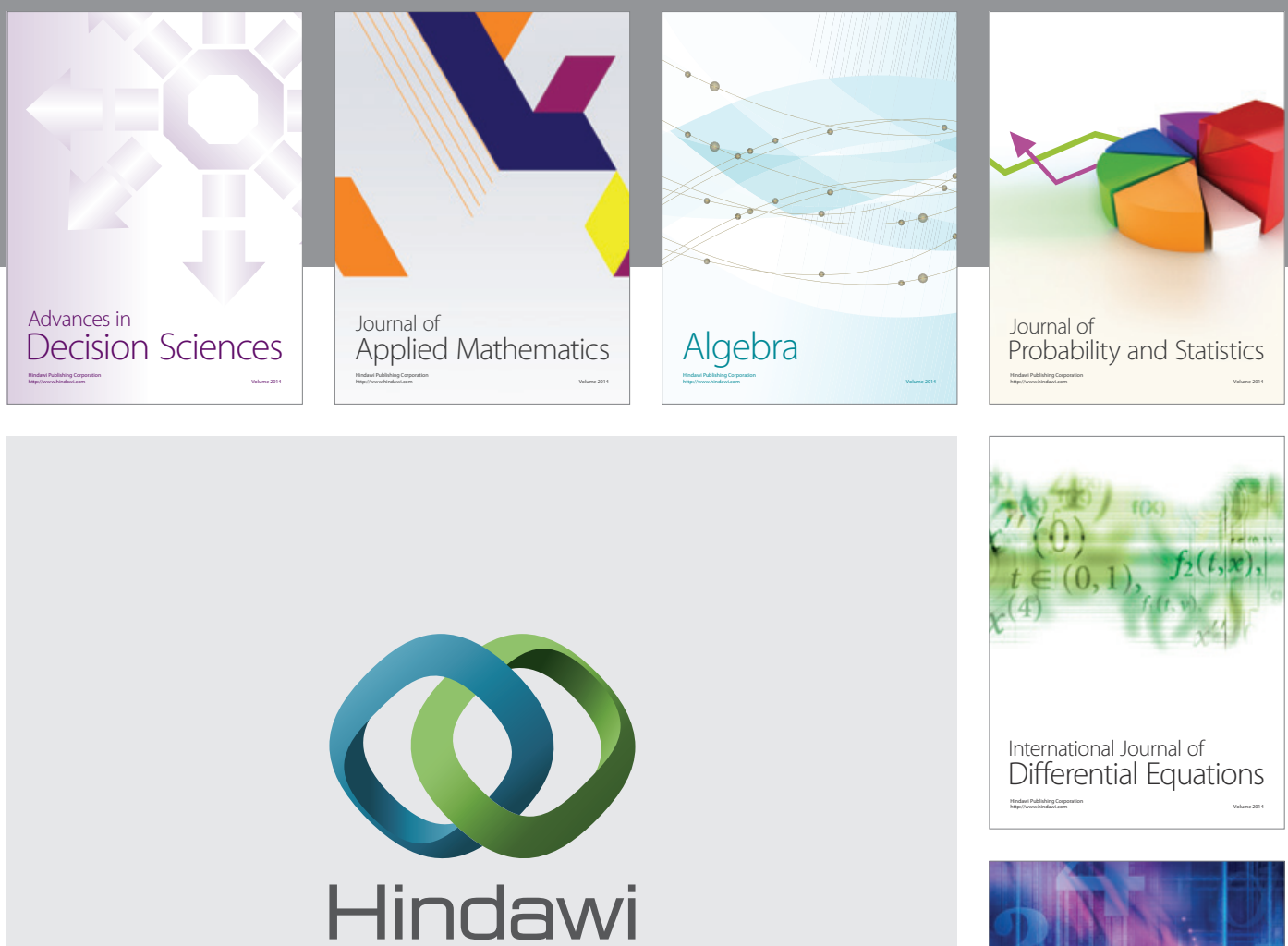

Submit your manuscripts at http://www.hindawi.com
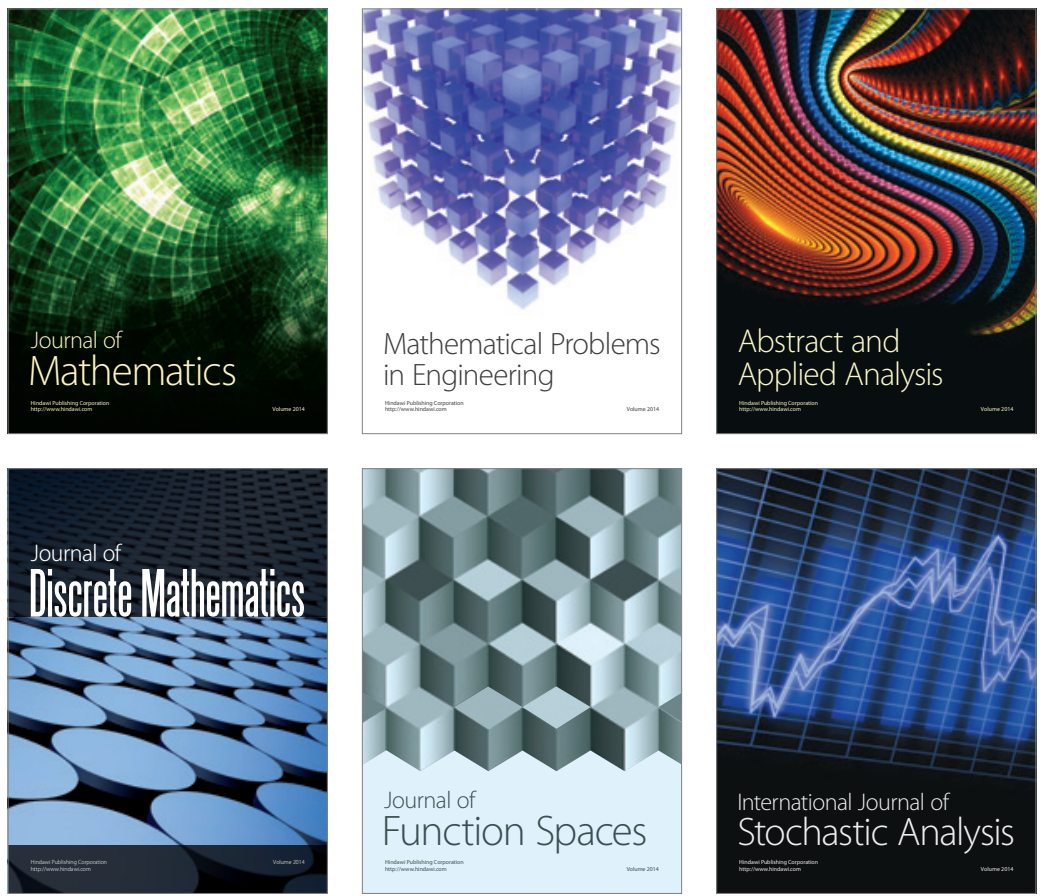

Journal of

Function Spaces

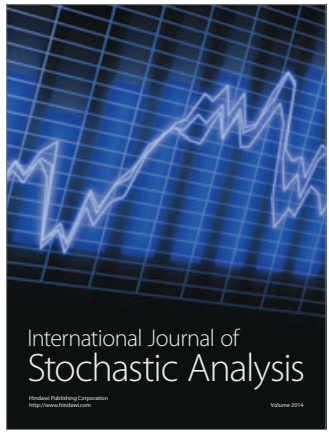

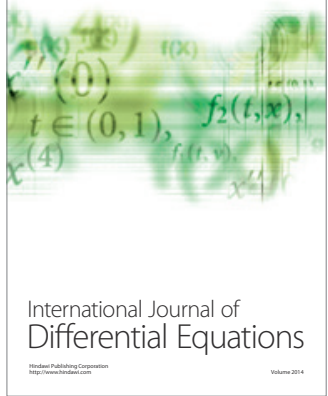
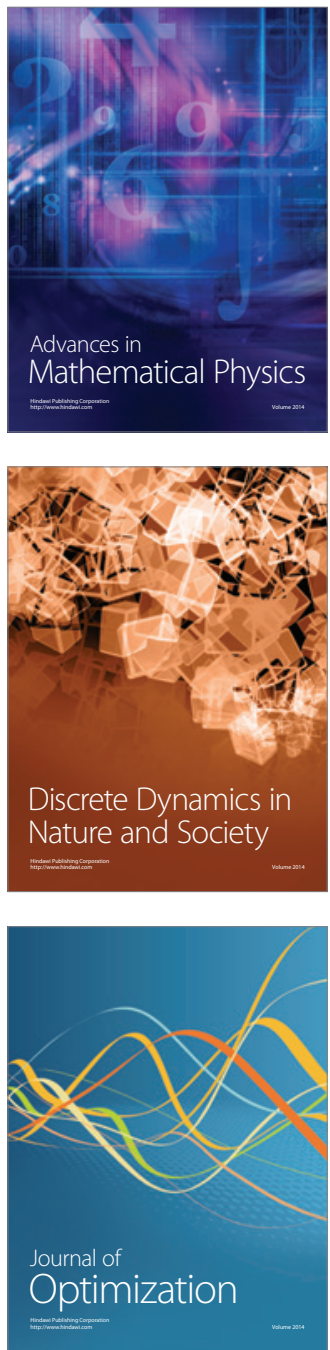